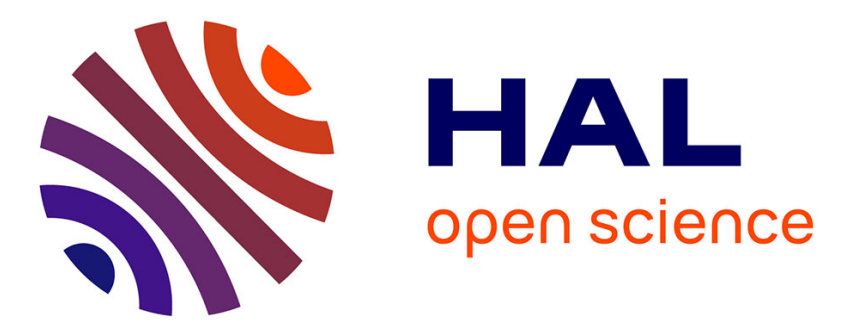

\title{
Titanium and iron modified delaminated muscovite as photocatalyst for enhanced degradation of Tetrabromobisphenol A by visible light
}

Nesrine Touaa, Zohra Bouberka, Chems-Eddine Gherdaoui, Philippe Supiot, Pascal Roussel, Christel Pierlot, Ulrich Maschke

\section{To cite this version:}

Nesrine Touaa, Zohra Bouberka, Chems-Eddine Gherdaoui, Philippe Supiot, Pascal Roussel, et al.. Titanium and iron modified delaminated muscovite as photocatalyst for enhanced degradation of Tetrabromobisphenol A by visible light. Functional Materials Letters, 2020, Functional Materials Letters, 13 (03), pp.2051008. 10.1142/S179360472051008X . hal-02415370

\section{HAL Id: hal-02415370 \\ https://hal.univ-lille.fr/hal-02415370}

Submitted on 8 Jan 2021

HAL is a multi-disciplinary open access archive for the deposit and dissemination of scientific research documents, whether they are published or not. The documents may come from teaching and research institutions in France or abroad, or from public or private research centers.
L'archive ouverte pluridisciplinaire HAL, est destinée au dépôt et à la diffusion de documents scientifiques de niveau recherche, publiés ou non, émanant des établissements d'enseignement et de recherche français ou étrangers, des laboratoires publics ou privés. 
Functional Materials Letters

Vol. 1, No. 1 (2015) Article number

(c) World Scientific Publishing Company

\title{
Titanium and iron modified delaminated muscovite as photocatalyst for enhanced degradation of Tetrabromobisphenol A by visible light
}

\author{
Nesrine Dalila Touaa*, Chems Eddine Gherdaoui ${ }^{*}{ }^{\dagger}$, Zohra Bouberka*, $^{\dagger}$, Philippe Supiot $^{\ddagger}$, Pascal Roussel $^{\S}$, Christel Pierlot $^{\S}$, \\ and Ulrich Maschke ${ }^{\dagger, * *}$ \\ "Laboratoire Physico-Chimie des Matériaux-Catalyse et Environnement (LPCM-CE), \\ Université des Sciences et de la Technologie d'Oran Mohamed Boudiaf (USTOMB) \\ BP 1505, El M'naouer, 31000 Oran, Algeria
}

${ }^{\dagger}$ Unité Matériaux et Transformations - UMET (UMR CNRS N8207)

Université de Lille - Faculté des Sciences et Technologies, 59655 Villeneuve d'Ascq Cedex, France

*ulrich.maschke@univ-lille.fr

${ }^{\ddagger}$ IEMN-P2M group, UMR 8520 (CNRS)

Université de Lille - Faculté des Sciences et Technologies, 59655 Villeneuve d'Ascq Cedex, France

\author{
${ }^{\S}$ Ecole Nationale Supérieure de Chimie de Lille, Cité Scientifique \\ BP 90108, 59652 Villeneuve d'Ascq Cedex, France
}

\author{
Received Day Month Year; Revised Day Month Year
}

\begin{abstract}
A new heterostructured titanium-iron-based material dispersed in alkaline muscovite (Ti-Fe-Mus) was synthesized by a typical impregnation process, and characterized by X-ray diffraction, adsorption/desorption of liquefied nitrogen and thermogravimetric/differential thermal analysis. This characterization suggests that the Ti-Fe-Mus system does not present sufficiently ordered silicate layers, but has a delaminated structure. The specific surface area and porosity have been significantly improved compared to the virgin muscovite, and the outer surface appears to be the dominant active surface. In particular, the Ti-Fe-Mus system was examined as a photocatalyst for the degradation of Tetrabromobisphenol A (TBBPA) selected as a model compound by visible light exposure. The Ti-Fe-Mus system showed excellent photocatalytic activity for TBBPA degradation and optimum catalyst concentration was found at $0.4 \mathrm{~g} \mathrm{~L}^{-1}$. More than $60 \%$ by weight of parent TBBPA with an initial concentration of $300 \mathrm{ppm}$ were eliminated after $120 \mathrm{~min}$ at $\mathrm{pH}=3$. Acid conditions have resulted in a faster elimination compared to alkaline and neutral conditions. Based on these results, it has been shown that titanium and iron modified delaminated muscovite (Ti-Fe-Mus) has strong potential for application as a powerful photocatalyst for the elimination of persistent organic pollutants present in the environment.
\end{abstract}

Keywords: Muscovite; persistent organic pollutant; Tetrabromobisphenol A; photolysis; photocatalysis.

\section{Introduction}

Titanium dioxide $\left(\mathrm{TiO}_{2}\right)$ photocatalysts are widely investigated for the degradation of organic pollutants, as they are readily available, photoactive, biologically and chemically inert, and relatively inexpensive. ${ }^{1-7}$ Recently, $\mathrm{TiO}_{2}$ clays generated significant interest; ${ }^{8-10}$ therefore, these materials have been applied as photocatalysts for effective treatment of waste water containing toxic organic compounds. Some attempts have been made to develop heterogeneous catalysts prepared by loading iron oxide (III) on porous media such as clay, activated carbon and graphite using more or less

** corresponding author. simple techniques. ${ }^{11}$ Clay materials are attractive to immobilize catalysts, and mica represents one of the most popular and stable mineral species. ${ }^{12,13}$

Recently, photo-catalysts based on $\mathrm{Fe}-\mathrm{TiO}_{2}$ delaminated clays were designed as a set of inorganic structured materials. ${ }^{14}$ Incorporation of a metal ion $\left(\mathrm{Fe}^{3+}\right)$ within a anatase structure is necessary to move the band-gap value to the visible light region, in order to obtain increased photocatalytic activity of the modified $\mathrm{TiO}_{2} .{ }^{15}$

To the best of our knowledge, the application of Ti-Femuscovite to the decontamination of persistent organic pollutants has not yet been reported. Ti-Fe-muscovite was therefore applied to catalyze the photodegradation of Tetrabromobisphenol A (TBBPA) as a model compound. 
TBBPA still represents one of the most commonly used brominated flame retardants in the world, although it may lead to biotoxicity, including immunotoxicity, neurotoxicity, endocrine disruption and cytotoxicity. ${ }^{16}$ Elimination of this compound remains difficult because TBBPA has very limited water solubility. ${ }^{17}$ The degradation of TBBPA under anaerobic and aerobic conditions was found to be ineffective. ${ }^{18}$ Advanced oxidation processes, on the other hand, represent appropriate techniques to decontaminate TBBPA. ${ }^{19,20}$

In addition, this study aims to valorize local low cost geological materials, without mineral interest. In this work, Ti-Fe-muscovite was synthesized, characterized and used to investigate photo-induced reduction of TBBPA.

\section{Materials and methods}

\subsection{Starting Materials}

Muscovite was obtained from a deposit at Timimoun (Algeria). Its structural formula is $\left(\mathrm{K}_{1.46} \mathrm{Mn}_{0.01} \mathrm{Ca}_{0.29} \mathrm{Ti}_{0.11}\right)$ $\left(\mathrm{Si}_{6.93} \mathrm{Al}_{1.07}\right)\left(\mathrm{Al}_{1.95} \mathrm{Fe}_{2.35} \mathrm{Mg}_{0.80}\right) \mathrm{O}_{20}(\mathrm{OH})_{4}$, designated as "Mus". The $\mathrm{pH}$ of the suspension of Mus $(\mathrm{pH}=7.52)$ appeared slightly alkaline, because muscovite, which has only siliceous faces, can trap protons in aqueous solution. The layer to layer cleavage of muscovite surface exposes $\mathrm{K}^{+}$, which can easily undergo hydrolysis and separate from surface. The surface of cleavage of muscovite being extremely hydrophilic and negatively charged, the cation exchange capacity (CEC) of Mus was found as 21.60 meq/100 g. ${ }^{21}$ All reagents were of chemical grade (SigmaAldrich) and used as received.

\subsection{Preparation of the catalyst}

A muscovite dispersion (20\% in clay mass) was mixed with $\mathrm{NaOH}(5 \mathrm{M})$ under vigorous agitation, then $1 \mathrm{M}$ of solution of $\mathrm{FeCl}_{3} 6 \mathrm{H}_{2} \mathrm{O}\left(\mathrm{OH}^{-} / \mathrm{Fe}^{3+}=5\right)$ was added in a ratio of 50 mmol of $\mathrm{Fe}^{3+}$ per gram of clay, and maintained under agitation at $35^{\circ} \mathrm{C}$. The end value of the $\mathrm{pH}$ was 3.5 . Then, the solid was prepared by impregnation by wet process of $\mathrm{Ti}$ (IV) ions on solid Fe-Muscovite. After 5 min of agitation, $12 \mathrm{~mL}$ of concentrated $\mathrm{TiCl}_{4}$ was added drop by drop under vigorous agitation (Fig. 1). The dissolution of muscovite is associated with a high consumption of acid and the formation of a very viscous gel structure. ${ }^{22}$ This gel was maintained at $50^{\circ} \mathrm{C}$ during $48 \mathrm{~h}$ before being washed until chloride free as indicated by the $\mathrm{AgNO}_{3}$ test. The final product "Ti-Fe-Mus" was dried at $100^{\circ} \mathrm{C}$ for 4 months and was gently crushed in an agate mortar.

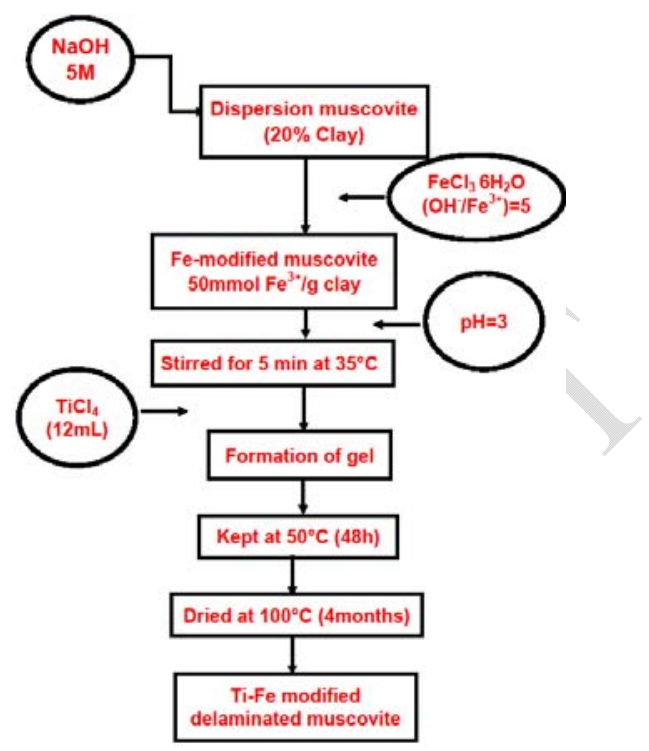

Fig. 1. Synthesis of Ti-Fe-muscovite by impregnation method.

\subsection{Characterization methods}

The chemical composition was obtained by fluorescence spectrometry (Philips Magix-Pro). The results were reported in mass $\%$ of oxides for the major elements. X-ray diffraction measurements were carried out at room temperature using the diffractometer Siemens D-5000 with $\mathrm{Cu} \mathrm{K}$ radiation. The X-ray tube was operated at $40 \mathrm{kV}$ with a beam current of $30 \mathrm{~mA}$ in the range $2 \theta=2-60^{\circ}$ at a scanning rate of $2^{\circ} 2 \theta \mathrm{min}^{-1}$. The database JCPDS (Joint Committee for Powder Diffraction Data-International Centre for Diffraction Data) was used to analyze the diffraction peaks. The surface of the solids was determined by adsorption of $\mathrm{N}_{2}$ at $77 \mathrm{~K}$ using Micromeritics ASAP 2010, after outgassing the samples at $80^{\circ} \mathrm{C}$ during $12 \mathrm{~h}$. The total surface area (SBET) was quantified by the BET method, while external or non-microporous surface area (SEXT) and the presence of micropores were estimated by the t-plot method. The distribution of the size of the micropores was analyzed according to the methods suggested by Horváth and Kawazoe. ${ }^{23}$ The method of Barrett-Joyner-Halenda (BJH) was used to evaluate the average diameter of pores (APD).

Thermogravimetric analysis (TGA) combined with Differential Thermal Analysis (DTA) was carried out by using Perkin-Elmer Pyris 1 presenting a resolution in mass of $1 \mu \mathrm{g}$. The average mass of the samples was of $8 \mathrm{mg}$ (Platinium-HT-pans) and thermal analysis was performed under $\mathrm{N}_{2}$, while following a heating rate of $10^{\circ} \mathrm{C} \mathrm{min}^{-1}$ from $20^{\circ} \mathrm{C}$ to $800^{\circ} \mathrm{C}$. Zeta potential measurements were carried out at room temperature with a Zetasizer (Nano-ZS model, Malvern Instruments, England) by using samples with a 
solid/liquid ratio of $1 \mathrm{mg}(3 \mathrm{~mL})^{-1}$. The infra-red absorption spectra (IR) were determined in transmission mode in the range from 4000 to $400 \mathrm{~cm}^{-1}$ using a spectrophotometer PHILIPS PU 9714. Mixtures of $99 \mathrm{mg}$ pure $\mathrm{KBr}$ and $1 \mathrm{mg}$ of sample were compressed under vacuum at room temperature.

\subsection{Photodegradation experiment}

Investigation on photocatalytic degradation was carried out by using TBBPA as model compound (CAS number: 79-947), purchased from Albermarle company (99\%). TBBPA is almost insoluble in water (20-30 ppm), with a partial solubility in acetone, chlorobenzene and o-xylene. ${ }^{24}$ Tetrahydrofuran (THF) was obtained from Sigma Aldrich in HPLC quality.

Aliquots of solutions containing $0.35 \mathrm{~mL}$ of TBBPA dissolved in $\mathrm{THF} / \mathrm{H}_{2} \mathrm{O}(80 / 20, \mathrm{~V} / \mathrm{V})$ and a photocatalyst were placed in Hellma quartz cells and were subjected to visible irradiation. At suitable exposure periods without interruption, i.e. no conduction of cumulated experiments; the vials were withdrawn from light exposure followed by immediate analysis. All experiments were repeated at least twice and average values are presented. The concentration of TBBPA was controlled by HPLC (Flexar, Perkin Elmer, USA), equipped with a UV detector and a symmetry column C18 (250 $\mathrm{mm} \times 4.5 \mathrm{~mm})$. The mobile phase consisted of acetonitrile (HPLC quality, Sigma-Aldrich) and of bidistilled purified water $(90: 10)$, flow rate $\left(1 \mathrm{~mL} \mathrm{~min}^{-1}\right)$, volume of injection $0.2 \mu \mathrm{L}$. Since the Flexar system was equipped with an array of photodiodes, the whole wavelength spectrum can be detected. The degradation of the TBBPA was determined by

$$
\text { TBBPA degradation }(\%)=\frac{[T B B P A]_{0}-[T B B P A]_{t}}{[T B B P A]_{0}} \times 100
$$

where $[T B B P A]_{0}$ and $\left[T B B P A_{t}\right.$ represent remaining TBBPA concentrations before $(\mathrm{t}=0)$ and after an exposure time period $(\mathrm{t})$, respectively. The pseudo first-order rate $\mathrm{k}$ $\left(\mathrm{min}^{-1}\right)$ was estimated by non-linear least square regression analysis via

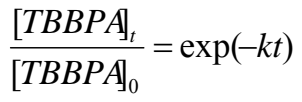

\subsection{Photoreactor and light source}

The irradiation processes were conducted at room temperature with $10 \mathrm{~mm}$ thick cells and the light was directed perpendicular to the cell. A source of Xenon light of $150 \mathrm{~W}$ (Hamamatsu LC8) associated with an optical fiber was applied, characterized by an emission spectrum covering a wide range of the UV-visible spectrum with a broad maximum in the visible region. The distance between fiber and the cell was fixed at $3 \mathrm{~cm}$. The constant agitation of the solution was maintained by a vibration stirrer. The reactional solution was initially agitated during $30 \mathrm{~min}$ in the darkness to reach adsorption equilibrium.

\section{Characterization of muscovite}

The powder X-ray diffraction pattern of Ti-Fe-Mus compared to Mus is presented in Fig. 2. Mus exhibits peaks at $(2 \theta)$ values $8.85(9.92 \AA), 17.75$ (4.99 $\AA), 19.85$ (4.47 $\AA), 26.66(3.33 \AA)$ and $36.02(2.49 \AA)$ corresponding to the planes [001], [002], [020], [101] and [112], respectively. That indicates the presence of muscovite, (JCPDF $\mathrm{N}^{\circ} 84$ 1306). The peaks with $(2 \theta)$ values of 12.35 (7.16 $\AA$ ), 25.02 $(3.55 \AA)$ and $28.05(3.18 \AA)$ correspond respectively to [001], [002], [112] planes, indicating presence of kaolinite (JCPDF 05-0221). The peaks with $(2 \theta)$ values of 20.85 $(4.22 \AA) 26.66(3.33 \AA), 50.00(1.80 \AA)$ and 60 (1.54 $\AA)$ correspond to the planes [110], [101] [112] [211], indicating the presence of quartz, (JCPDS 27-0605). The peaks at ( $2 \theta$ ) of $19.94^{\circ}, 25.21^{\circ}$ and $33.31^{\circ}$ are assigned to the nonbasal two-dimensional reflections $\mathrm{hk}$ resulting from the diffraction of the random stacking of layers, which proved to be strongest in unoriented crystals. ${ }^{25,26}$

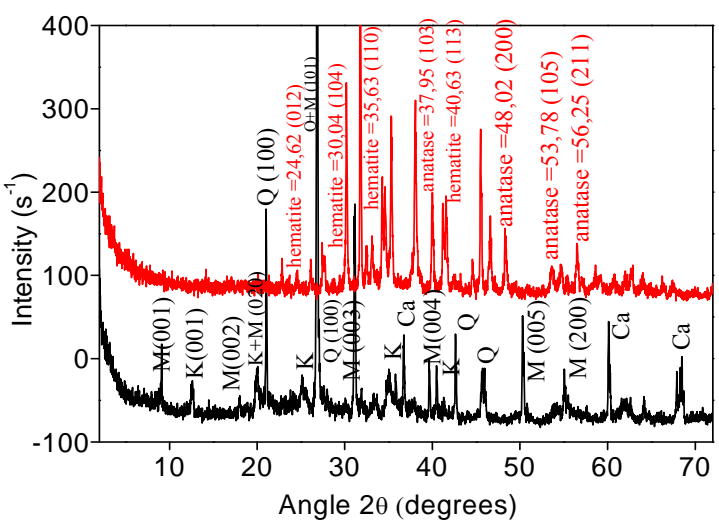

Fig. 2. XRD patterns of Mus (lower diffractogram in black color) and TiFe-Mus (upper diffractogram in red color).

The $\mathrm{Ti}$ and $\mathrm{Fe}$ introduction into layered clay resulted in significantly different XRD patterns; in particular the intensity decreased compared to Mus. The disappearance of the $\mathrm{d}_{001}$ reflection together with the loss of other (001) reflections, characteristic of muscovite and kaolinite, indicates disordering of the clay sheets in the c-direction, which can be associated to their delamination: The diffuse XRD pattern observed for $\mathrm{TiO}_{2}$-PILC indicates a highly disordered structure, similar to that previously observed for 
$\mathrm{Fe}_{2} \mathrm{O}_{3}$ PILC. ${ }^{25}$ The presence of a broad range of hydrolyzed $\mathrm{Ti}$ species of different sizes (such as monomeric $\mathrm{TiO}^{2+} / \mathrm{Ti}(\mathrm{OH})_{2}{ }^{2+}$ and polymeric species $)^{27}$ in the pillaring solution causes non-uniform pillaring of clay layers. ${ }^{28}$ Tchoubar and Bergaya suggested that the hydrated iron species could aggregate together and become larger in size at higher $\mathrm{OH}^{-} / \mathrm{Fe}^{3+}$ ratio, ${ }^{29,30}$ resulting in delamination of certain host clay particles and the absence of long range face-to-face stacking of the clay layers. Indeed, the reflections are diffuse and of low intensity, which does not allow their observation on X-ray patterns. Several photocatalysts containing clay have been reported using layered montmorillonites and $\mathrm{TiO}_{2}$ as an active phase. These reports are mainly centered on the improvement of porosity by delamination of structures and anchorage of other semiconductors, such as $\mathrm{ZnO}, \mathrm{Bi}_{2} \mathrm{O}_{3}$, silver halides, and other ternary oxides, ${ }^{31}$ necessary to study the relation between semiconductors and clay materials for the photocatalytic reaction. With regard to the XRD pattern of $\mathrm{Fe}_{2} \mathrm{O}_{3}$-pillared Montmorillonite, Mandalia et al. attributed the broad XRD peak in the area of very low $2 \theta$ angles to certain disordered solids, ${ }^{32}$ such as porous silica, ${ }^{33}$ molecular sieves containing silica $^{34}$ and biogenetic mesoporous silica, ${ }^{35}$ which cannot be attributed to simple intercalation of iron hydroxyl cations, ${ }^{29}$ but to the existence of a porous structure.

XRD patterns of Ti-Fe-Mus show peaks with $2 \theta$ values of $26.66^{\circ}, 37.95^{\circ}, 48.02^{\circ}, 53.78^{\circ}$ and $56.25^{\circ}$ corresponding to the planes $(101),(103),(200),(105)$ and (211) of anatase type (JCPDS No. 21-1272). The peaks with $2 \theta$ values of $24.62^{\circ}, 30.04^{\circ}, 35.63^{\circ}, 40.63^{\circ}$ can be attributed to $(012)$, (104), (110) and (113) crystalline structures, corresponding to hematite (JCPDS file Card, No. 33-0664).

Table 1. Chemical composition of Mus; Ti-Fe-Mus (TFM); Ti-Fe-Mus (REC) (recovered after four photodegradation cycles).

\begin{tabular}{ccccccccc}
\hline Sample & $\begin{array}{l}\mathrm{SiO}_{2} \\
\text { (mass\%) }\end{array}$ & $\begin{array}{l}\mathrm{Al}_{2} \mathrm{O}_{3} \\
\text { (mass\%) }\end{array}$ & $\begin{array}{l}\mathrm{Fe}_{2} \mathrm{O}_{3} \\
\text { (mass\%) }\end{array}$ & $\begin{array}{l}\mathrm{CaO} \\
\text { (mass\%) }\end{array}$ & $\begin{array}{l}\mathrm{MgO} \\
\text { (mass\%) }\end{array}$ & $\begin{array}{l}\mathrm{MnO} \\
\text { (mass\%) }\end{array}$ & $\begin{array}{l}\mathrm{K}_{2} \mathrm{O} \\
\text { (mass\%) }\end{array}$ & $\begin{array}{l}\mathrm{TiO}_{2} \\
\text { (mass\%) }\end{array}$ \\
\hline Mus & 47.72 & 17.66 & 21.56 & 1.90 & 3.70 & 0.13 & 7.92 & 1.01 \\
$\mathrm{TFM}$ & 15.32 & 8.36 & 67.68 & 0.41 & ---- & ---- & 1.18 & 5.54 \\
$\mathrm{REC}$ & 15.43 & 8.32 & 67.92 & 0.36 & ---- & ---- & 1.12 & 5.34 \\
\hline
\end{tabular}

Table 1 summarizes the data of chemical composition of Mus and Ti-Fe-Mus determined by XRF. Mus is characterized by high percentages of $\mathrm{SiO}_{2}$ and $\mathrm{Al}_{2} \mathrm{O}_{3}$, representing principal oxides. The elements $\mathrm{Si}$ - and $\mathrm{Al}$ - are generally associated with structures of clay, quartz and feldspars. The ratio $\mathrm{SiO}_{2} / \mathrm{Al}_{2} \mathrm{O}_{3}=2.7$ is thus greater than 1 , and is in the interval most frequently published from 2.3 to $5 .{ }^{36,37}$ A high quantity of $\mathrm{K}_{2} \mathrm{O}$ was found, indicating the presence of muscovite/illite mica, also confirmed by XRD. This finding shows indirectly that clay presents important contents of collapsed layered-clay phases, because potassium is generally strongly placed in the ditrigonal holes of the tetrahedral layers, thus preventing any subsequent process of exchange of ions. ${ }^{38,39}$ A high percentage of magnesium suggests that $\mathrm{Mg}$ belongs to the internal structure. ${ }^{40}$ The red colour is due to the iron oxide abundance (21.56 wt.\%), indicating that this clay is a ferric aluminosilicate; $\mathrm{Fe}_{2} \mathrm{O}_{3}$ can be present as a part of the structure, can serve as isomorphic substitution at the same time of $\mathrm{Si}$ and $\mathrm{Al}$ inside the layered structure, or as separate phases rich in Fe like phases of impurity on the surface of the sheet in form of extra-structural oxides. A noticeable increase of $\mathrm{TiO}_{2}$ (5.5 wt.\%) was observed for Ti-Fe-Mus, compared to $1.0 \mathrm{wt} . \%$ for Mus. A spectacular increase of $\mathrm{Fe}_{2} \mathrm{O}_{3}$ was also observed, passing from $21.5 \mathrm{wt} . \%$ for Mus up to 67.6 wt.\% for Ti-Fe-Mus (Table 1). The reduction of aluminium, potassium and magnesium of the clay structure after modification can be attributed to the conditions of $\mathrm{pH}$. The $\mathrm{pH}$ treatment reduces $\mathrm{CEC},{ }^{41}$ and can also release elements from the octahedral sheet. ${ }^{42}$ The textural parameters are given in Table 2. According to IUPAC classification, both clay samples presented isotherms having a profile similar to that of the IVa type, exhibiting a welldefined H3 hysteresis loop. ${ }^{43}$ The physisorption isotherms of type IV are associated with a capillary condensation

Table 2. Specific surface area $\left(\mathrm{S}_{\mathrm{BET}}\right)$, external surface area $\left(\mathrm{S}_{\mathrm{ext}}\right)$ and micropore volume $\left(\mathrm{V}_{\mu \mathrm{P}}\right)$ of Mus and Ti-Fe-Mus catalyst. $\mathrm{V}_{\mathrm{m}}$ : monolayer capacity derived from BET treatment. $\mathrm{S}_{\text {tot }}$ : Total surface area derived from the slope of the straight line passing through the origin of the t-plot. $V_{\mu p}$ : Liquid micropore volume derived from the ordinate at the origin in the second straight line of the t-plot. $\mathrm{S}_{\mathrm{ext}}$ micro: Surface area out of micropores derived from the slope of the second straight line of the t-plot. $\mathrm{V}_{\text {tot }}$ : Total pore volume (TPV), derived from the amount of nitrogen adsorbed at $\mathrm{P} / \mathrm{P}_{0}$ of 0.995 .

\begin{tabular}{|c|c|c|c|c|c|c|c|}
\hline \multirow[b]{3}{*}{ Samples } & \multirow[b]{3}{*}{$\begin{array}{c}\mathrm{S}_{\mathrm{BET}} \\
\left(\mathrm{m}^{2} \mathrm{~g}^{-1}\right)\end{array}$} & \multirow[b]{3}{*}{$\begin{array}{c}\mathrm{V}_{\mathrm{m}} \\
\left(\mathrm{cm}^{3} \mathrm{~g}^{-1}\right)\end{array}$} & \multirow[b]{3}{*}{$\begin{array}{c}\mathrm{S}_{\mathrm{ext}} \\
\left(\mathrm{m}^{2} \mathrm{~g}^{-1}\right)\end{array}$} & \multirow[b]{3}{*}{$\begin{array}{c}\mathrm{S}_{\mathrm{tot}} \\
\mathrm{m}^{2} \mathrm{~g}^{-1}\end{array}$} & \multirow{2}{*}{\multicolumn{2}{|c|}{$\begin{array}{l}\text { Horvath- } \\
\text { Kawazoe } \\
\end{array}$}} & \multirow[b]{3}{*}{$\begin{array}{l}\text { TPV } \\
\left(\mathrm{cm}^{3} \mathrm{~g}^{-1}\right)\end{array}$} \\
\hline & & & & & & & \\
\hline & & & & & $\begin{array}{c}\mathrm{V}_{\mu \mathrm{P}} \\
\left(\mathrm{cm}^{3} \mathrm{~g}^{-1}\right)\end{array}$ & $\begin{array}{c}\text { APD } \\
(\AA)\end{array}$ & \\
\hline Muscovite & 3.6164 & 0.8307 & 4.3272 & 5.5104 & 0.0068 & 86.8294 & 0.0136 \\
\hline Ti-Fe-Mus & 44.6502 & 10.2568 & 55.1578 & 65.8283 & 0.0533 & 58.4612 & 0.0775 \\
\hline
\end{tabular}

occurring in the mesopores, limiting absorption on a wide range of $P / P_{0}$, and monolayer-multilayer characteristics of adsorption at the initial isotherm part. A H3 hysteresis corresponds to a system formed by slit-shaped pores having a vertical adsorption branch at a relative pressure near to one, and a branch of desorption roughly at medium pressure. The curves of adsorption and desorption of Mus (Fig. 3(a)) and Ti-Fe-Mus (Fig. 3(b)) overlapped when $P / P_{0}$ was lower than 0.4 , which revealed the existence of small 
micropores and monolayer adsorption. The quantity of adsorption of $\mathrm{N}_{2}$ for Mus and Ti-Fe-Mus increased quickly when $P / P_{0}$ was higher than 0.4 , which was caused by mesopore filling. The isothermal profiles and the loops of hysteresis indicated that the samples had a porous structure
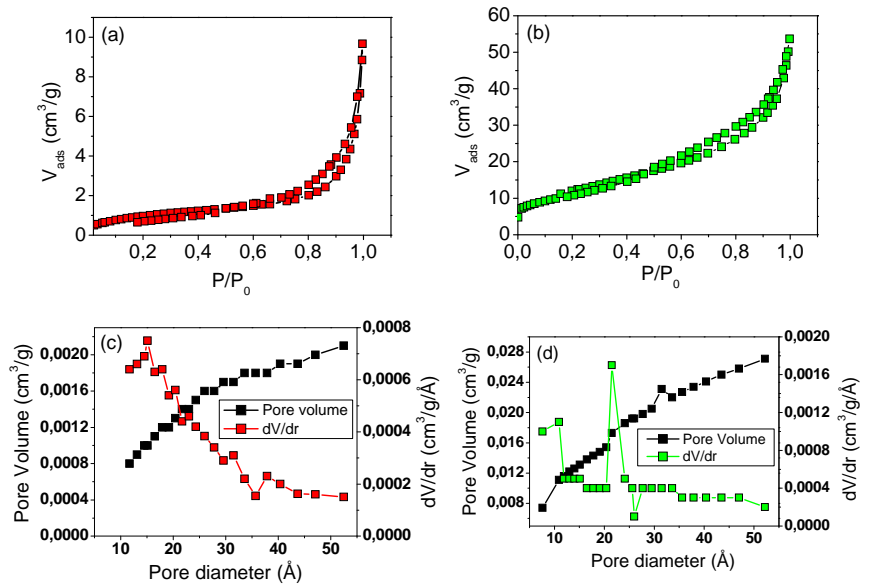

Fig. 3. $\mathrm{N}_{2}$ adsorption-desorption isotherms of (a) Mus and (b) Ti-Fe-Mus. The corresponding pore size distributions are shown as well for (c) Mus, and (d) Ti-Fe-Mus.

formed essentially of mesopores, associated with certain micropores, mainly with the slit-like format. Table 2 gathers the results obtained from BET analysis. Specific surface areas $\left(\mathrm{S}_{\mathrm{BET}}\right)$ and the total volume of pores $\left(\mathrm{V}_{\mathrm{M}}\right)$ increased from $3.61 \mathrm{~m}^{2} \mathrm{~g}^{-1}$ to $44.6 \mathrm{~m}^{2} \mathrm{~g}^{-1}$ and from $0.83 \mathrm{~cm}^{3} \mathrm{~g}^{-1}$ to $10.25 \mathrm{~cm}^{3} \mathrm{~g}^{-1}$, while the average diameter of the pores decreased from $151.3 \mathrm{~nm}$ to $69.48 \mathrm{~nm}$ for Mus and Ti-FeMus, respectively. The $\mathrm{S}_{\mathrm{BET}}$ value of Mus was found to be lower than that reported in literature, ${ }^{44}$ due to the lower crystallinity in relationship with the presence of structural $\mathrm{SiOH}$ groups at crystal edge sites. During BET experiment, $\mathrm{N}_{2}$ molecules occupy not only the external surface, but also penetrate in the capillaries. The porosity of initial muscovite results from an arrangement named "house of cards". 45 Moreover, the volume of the micropores $\left(\mathrm{V}_{\mu \mathrm{p}}\right)$ accounted for $2 \%$ of the total pore volume (TPV). In Ti-Fe-Mus, clay particles and some hydrated $\mathrm{Fe}$ and $\mathrm{Ti}$ cations outside the interlamellar space could overlap, forming a secondary "house-of-cards" structure. Consequently, mesoporosity would result from the intersections of the overlapping. These results thus suggest that the external surface was the predominant active surface. Figures 3(c) and 3(d) show the evolution of the pore size distribution of Mus and Ti-FeMus, calculated from desorption experiments using the method of Barrett-Joyner-Halenda (BJH). Both figures show one peak dominating in the mesoporous range. The peak maximum of Mus at $8.63 \mathrm{~nm}$ was shifted to $5.84 \mathrm{~nm}$ for Ti-Fe-Mus, indicating a narrow pore size distribution of the photocatalyst.

The infrared spectra of Mus and Ti-Fe-Mus (Fig. 4) can be used for the identification of oxides and the distinction between the various forms of polymorphism. ${ }^{46}$ Important peaks at $3622 \mathrm{~cm}^{-1}$ and near $3699 \mathrm{~cm}^{-1}$ can be assigned to $\mathrm{OH}$ groups on the internal surface. The broad $\mathrm{OH}$-stretching

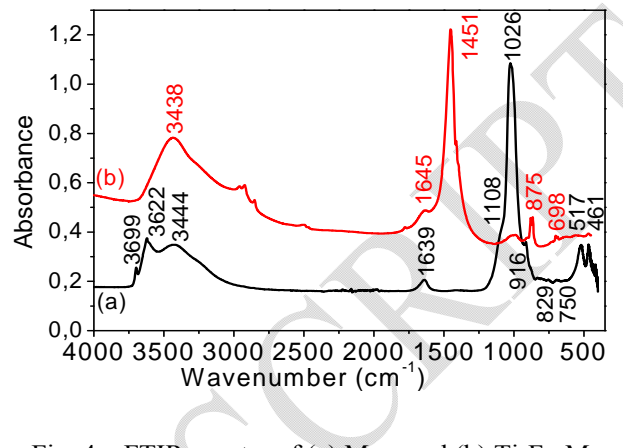

Fig. 4. FTIR spectra of (a) Mus, and (b) Ti-Fe-Mus.

band close to $3622 \mathrm{~cm}^{-1}$ coupled with the bands at $829 \mathrm{~cm}^{-1}$ and $750 \mathrm{~cm}^{-1}$ indicates the presence of muscovite. These bands come respectively from the $\mathrm{Al}-\mathrm{Mg}-\mathrm{OH}$ deformation ${ }^{46}$ and the Al-O-Si in-plane vibration. The peaks at $1026 \mathrm{~cm}^{-1}$ were assigned to bands characteristic of silicates which were mainly related to the stretching vibrations of $\mathrm{M}-\mathrm{O}$ (where $\mathrm{M}=\mathrm{Si}, \mathrm{Al})$, and agreed well in the range of $1103-1036 \mathrm{~cm}^{-}$ 1.47 These stretching vibrations of the $\mathrm{SiO}_{4}$ tetrahedrons produce a very broad band with two shoulders on the high frequency side and a shoulder on the low frequency side. The highest frequency band appears at $1108 \mathrm{~cm}^{-1}$, which is very weak and can be easily missed. The peak at $916 \mathrm{~cm}^{-1}$ appears at a frequency appreciably lower, indicating a deformation of the Al-Al-OH group, ${ }^{48,49}$ compared to the others, reflecting the influence of octahedral $\mathrm{Fe}$ and $\mathrm{Mg}$ on the spectrum. A vibration of the $\mathrm{Al}-\mathrm{Mg}-\mathrm{OH}$ band was observed at $829 \mathrm{~cm}^{-1}$ and the peak at $750 \mathrm{~cm}^{-1}$ was assigned to $\mathrm{Mg}-\mathrm{Fe}-\mathrm{OH}$. Vibrations of $\mathrm{Si}-\mathrm{O}$ and various modifications of silica ( 795 and $800 \mathrm{~cm}^{-1}$ ) were also observed by Akçay et al. ${ }^{50}$ and Vlasova et al. ${ }^{47}$ The bands at 517 and $461 \mathrm{~cm}^{-1}$ were attributed to coupled $\mathrm{Al}-\mathrm{O}$ and $\mathrm{Si}-\mathrm{O}$ out-of-plane vibrations.

Distinct changes were observed on the FTIR spectrum of Ti-Fe-Mus compared to Mus. The presence of a broad band centered at $3438 \mathrm{~cm}^{-1}$ of Ti-Fe-Mus is attributed to a silicate species, ${ }^{39}$ indicating a new substance, in agreement with $\mathrm{X}$ ray diffraction results. The bands at 3622 and 3699 $\mathrm{cm}^{-1}$ of Ti-Fe-Mus, reduced in intensity compared to Mus, can be attributed to the release of octahedral cations from the structure, and were confirmed by chemical analysis (Table 1). The band at approximately $1026 \mathrm{~cm}^{-1}$, due to the $\mathrm{Si}-\mathrm{O}$ stretching in the case of Mus, moved to $1451 \mathrm{~cm}^{-1}$ for 
Ti-Fe-Mus, which implies structural changes in the tetrahedral sheets. The absorption bands at 461 and $517 \mathrm{~cm}^{-1}$ can be attributed to bending vibrations of the Si-O band, which decrease for Ti-Fe-Mus. The presence of anatase in Ti-Fe-Mus could be detected around $698 \mathrm{~cm}^{-1}$.
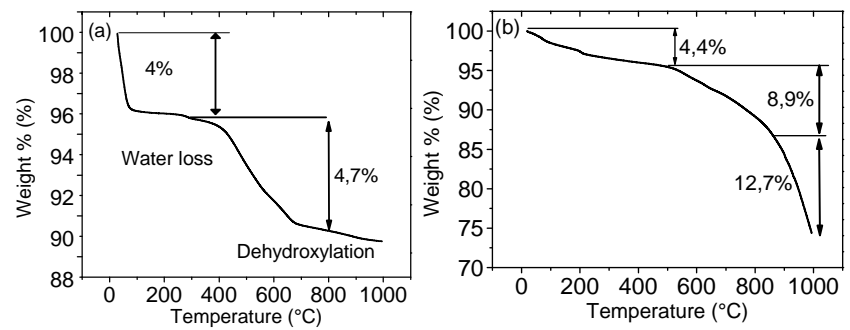

Fig. 5. TGA curves of (a) Mus and (b) Ti-Fe-Mus.

Figures 5(a)-5(b) show the results from TGA analysis of Mus and Ti-Fe-Mus, respectively. Figure 5(a) exhibits a relatively important loss of approximately 4 mass- $\%$ between room temperature and $100^{\circ} \mathrm{C}$, corresponding to water loss retained on the surface of the sample, mainly due to the high percentage of the fine fraction of this clay. The loss of mass in the range from 340 to $670^{\circ} \mathrm{C}(4.7$ mass- $\%)$ is due to the dehydroxylation of the clay. According to GridiBennadji et al., ${ }^{51}$ kaolinite is dehydroxylated between 450 and $550^{\circ} \mathrm{C}$ and muscovite between 475 and $950^{\circ} \mathrm{C}$. The loss of hydroxyl groups breaks the bonds between tetrahedral silicon and octahedral aluminium, destroying the laminar structure and transforming clay into metakaolinite.

Comparatively, the TGA curve of Ti-Fe-Mus (Fig. 5(b)) show a loss of 4.4 mass- $\%$ up to $200^{\circ} \mathrm{C}$, which can be attributed to adsorbed water loss. It is interesting to note that the weight loss in the case of Ti-Fe-Mus was quite higher than that for Mus, which indicates that Ti-Fe-Mus has a much stronger hydrophilic character. Moreover, several other thermal phenomena occurred in Ti-Fe-Mus, in particular that around $633^{\circ} \mathrm{C}$, which corresponds to a loss of approximately 8.9 mass- $\%$, ascribable to partial oxidation of $\mathrm{Ti}$ and $\mathrm{Fe}$ species impregnated in Mus. The high weight loss of 12.7 mass- $\%$ around $900^{\circ} \mathrm{C}$ can be attributed to the dehydration of polycations belonging to clay layers, which protect the intercalated structure against a possible structural rearrangement of the pillars.

SEM micrographs (Fig. 6) revealed modifications of texture of Mus and Ti-Fe-Mus: the morphology of Ti-FeMus is compact because of delamination, in agreement with the results from XRD, while muscovite presents flaky and large particles characteristic of muscovite. SEM images of Ti-Fe-Mus show many small well dispersed aggregates, which are probably broken platelets and agglomerates.
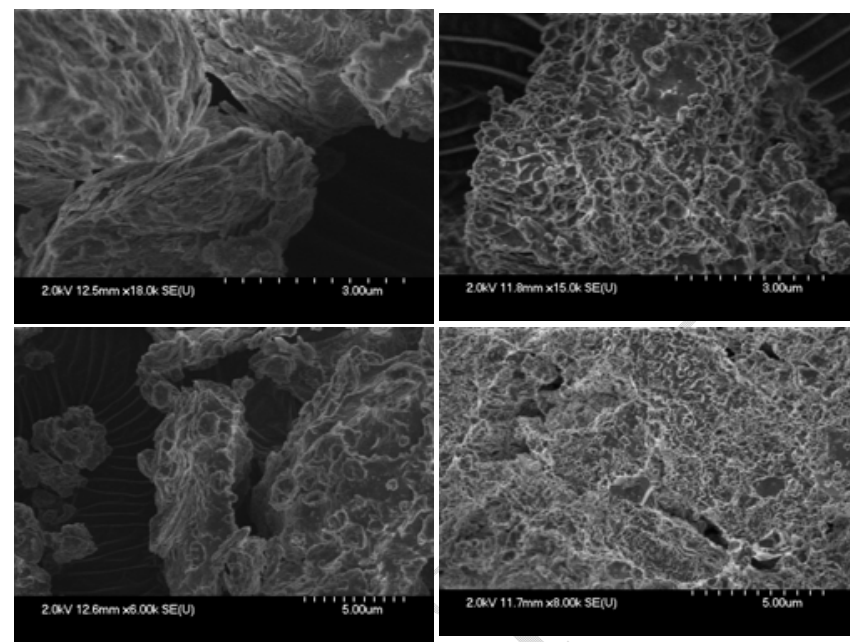

Fig. 6. SEM images for Mus (on the left) and Ti-Fe-Mus (on the right).

Figure 7 illustrates the effect of $\mathrm{pH}$ on the zeta potential of Mus and Ti-Fe-Mus. An increase of $\mathrm{pH}$ involved an increase of the negative charge of muscovite. The intersection of the curve with the $\mathrm{x}$-axis at zeta potential equal zero gives pHiep (iep $=$ isoelectric point). This material did not show a iep because isomorphic substitution remains independent of the $\mathrm{pH}$ in the acidic range. In the basic range, the edge surface of the muscovite, where the octahedral sheet is broken, can be compared with the surface of alumina or silica particles. The hydroxyl-ion acts like an ion determining the potential and causes a negative charge of the surface of the edge. ${ }^{21}$ Figure 7 also shows that Ti-Fe-Mus introduced a significant positive charge under acidic conditions, probably related to the formation of larger polyhydroxo complexes on the external surface of muscovite because of flocculation with high percentages of titanium and iron, involving a reduced electrophoretic mobility. The point of zero charge (pzc) of Ti-Fe-Mus occurs at $\mathrm{pH}=5.5$.

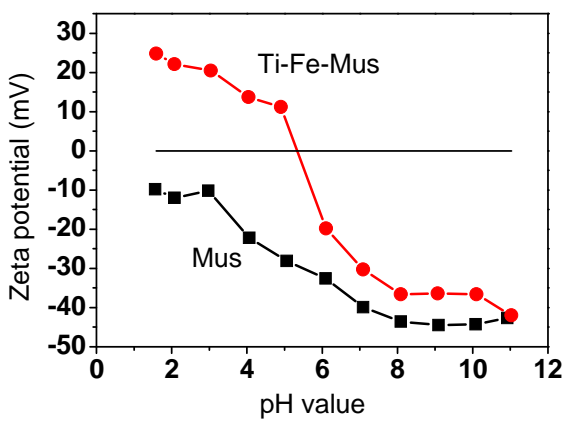

Fig. 7. Zeta potentials of Mus and Ti-Fe-Mus.

\section{Photocatalytic behavior}

No degradation of TBBPA without photocatalyst was observed in dark control samples. Moreover, tests of 
adsorption were carried out in the darkness to elucidate the role of the Ti-Fe-Mus surface on the adsorbed quantities of TBBPA. The elimination produced by Mus was zero after $120 \mathrm{~min}$ of reaction time and only $2 \mathrm{wt} . \%$ Ti-Fe-Mus was removed from the initial concentration after the same time. Figure 8 shows clearly that the photo-induced degradation of TBBPA by adding Ti-Fe-Mus as catalyst was faster and more efficient than photolysis. Moreover, pure Mus was applied as catalyst yielding nearly the same results as those obtained for photolysis. After $120 \mathrm{~min}$ of reaction time, more than $60 \mathrm{wt} . \%$ of TBBPA were removed by Ti-Fe-Mus, but only $40 \mathrm{wt} \%$ were eliminated by adding pure Mus, or by direct photolysis in the absence of catalyst.

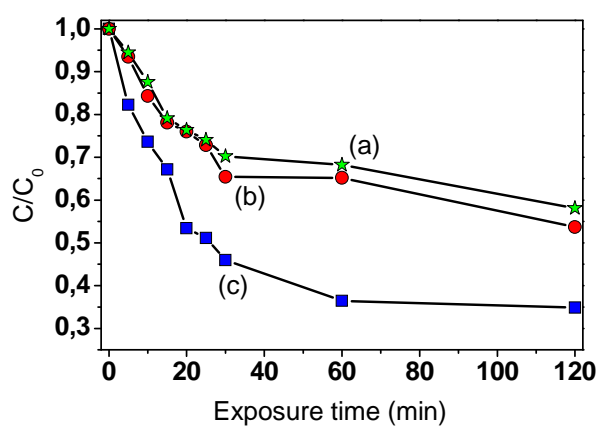

Fig. 8. Degradation of TBBPA under visible light (a) without catalyst, (b) with pure Mus as catalyst and (c) with Ti-Fe-Mus catalyst (concentration $30 \mathrm{mg} / 25 \mathrm{~mL}$ ). Other experimental conditions: TBBPA concentration 300 ppm; $\mathrm{pH}=3$ and $\mathrm{T}=25^{\circ} \mathrm{C}$.

Consequently, one can conclude that visible irradiation and presence of Ti-Fe-Mus particles are essential to obtain efficient photodegradation of TBBPA. Indeed, the Ti-FeMus catalyst presents high-performance photocatalytic efficiency by using luminous energy to create $\mathrm{e}-\mathrm{h}+$ pairs on the surface. The e-/h+ pairs are then available for the processes of degradation, which generally imply the formation of reactive oxygenated species, such as $\mathrm{HO}^{\circ}$ and $\mathrm{O}_{2}{ }^{-}$, which contribute then to the degradation of the pollutants.

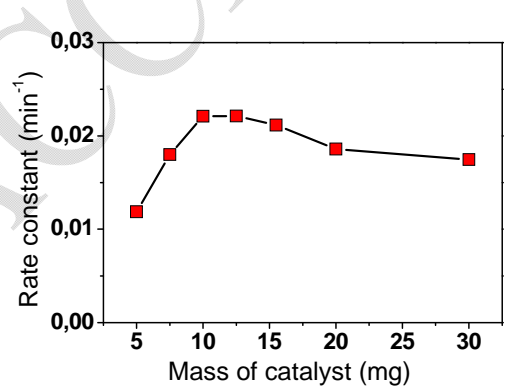

Fig. 9. Rate constants of TBBPA degradation with catalyst load varying from 5 to $30 \mathrm{mg}(\mathrm{V}=25 \mathrm{~mL})$. Experimental conditions: TBBPA concentration $300 \mathrm{ppm}$; exposure time $\mathrm{t}=120 \mathrm{~min} ; \mathrm{pH}=3$ and $\mathrm{T}=25^{\circ} \mathrm{C}$.
Figure 9 presents the effect of Ti-Fe-Mus mass on TBBPA degradation to determine the optimal catalyst loading needed for maximal photodegradation. The initial slope of the curve increases considerably by increasing the catalyst mass from 5 to $10 \mathrm{mg}$, and then the degradation rate remains almost constant. With the increase of the catalyst mass, the total active surface increases and thus more active sites are available on the catalyst surface, ${ }^{52}$ then, by increasing again the catalyst mass, the degradation rate starts to decrease. This can be explained by the aggregation of Ti-Fe-Mus particles with raised concentrations, involving a reduction of active sites on the surface, and a decrease of the penetration of visible light. ${ }^{53}$ The photocatalytic abatement of other organic pollutants also showed the same dependence with respect to the catalyst concentration. ${ }^{54}$ In the present work, it can be concluded from Fig. 9 that the optimal catalyst loading was $10 \mathrm{mg}$ of Ti-Fe-Mus in $25 \mathrm{~mL}$ TBBPA solution.

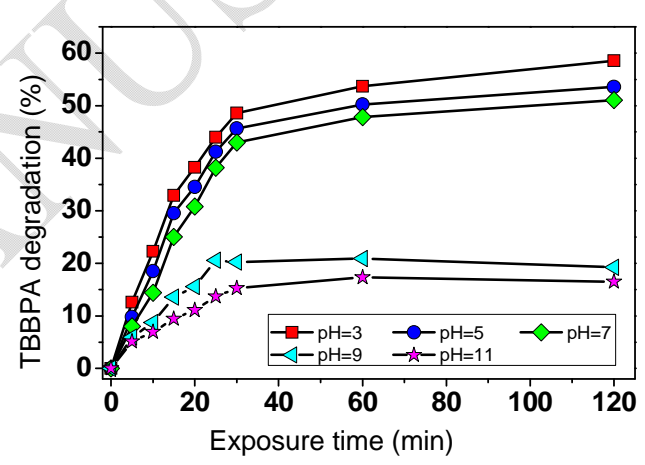

Fig. 10. Effect of $\mathrm{pH}$ on the photocatalytic degradation of TBBPA. Experimental conditions: Ti-Fe-Mus concentration $30 \mathrm{mg} / 25 \mathrm{~mL}$; TBBPA concentration $300 \mathrm{ppm}$ and $\mathrm{T}=25^{\circ} \mathrm{C}$.

The photocatalytic reactions were carried out in a range of $\mathrm{pH}$ values between 3 and 11, since hydroxyl and hydrogen ions affect considerably the dissociation of TBBPA and the catalyst surface during the process of oxidation. Figure 10 shows the percentage of degradation of TBBPA related to $\mathrm{pH}$ and exposure time, initially revealing a strong increase in the elimination of TBBPA, which becomes then constant during an exposure time from 60 to $120 \mathrm{~min}$. Moreover, the percentage of degraded TBBPA increased with the reduction of the $\mathrm{pH}$ value; the highest degradation occurred at $120 \mathrm{~min}$ exposure time with $\mathrm{pH}=3$ (60 wt.\%), and the lowest degradation with $\mathrm{pH}=11$ (16 wt.\%). An optimal degradation was thus achieved under acid conditions $(\mathrm{pH} \approx$ 3.0 ), and this $\mathrm{pH}$ value was maintained for all subsequent degradation experiments.

The interpretation of the effects of the $\mathrm{pH}$ on the efficiency of the process of photocatalytic degradation remains a difficult task because the photodegradation rates 
of TBBPA depend on the distribution of the various species of TBBPA and the other concomitants in the solvent (hydrogen donor), as well as on the Ti-Fe-Mus catalyst. Several authors reported that the efficiency of elimination of TBBPA increased with the reduction of the $\mathrm{pH}$ values, ${ }^{55-57}$ which corresponds to the results presented here. It was explained that the low $\mathrm{pH}$ values were beneficial for the debromination and the value of the highest debromination was obtained with $\mathrm{pH}=4$. On the other hand, a better removal efficiency of TBBPA in alkaline conditions was also reported ${ }^{58}$ which is explained by the fact that the higher $\mathrm{pH}$ can provide more hydroxide ions $\left(\mathrm{OH}^{-}\right)$to react with the holes and to form hydroxyl radicals, improving thereafter the degradation rate of TBBPA. As the effect of the $\mathrm{pH}$ cannot be generalized, Gogate and Pandit recommended to realize laboratory studies to establish the optimum $\mathrm{pH}$ conditions. ${ }^{59}$ It was shown that pzc for Ti-FeMus was equal to 5.5 (Fig. 7), above this value (TiFe-Mus) is mainly formed and with $\mathrm{pH}$ values lower than pzc, the catalyst surface is protonated to form (Ti-Fe-Mus) ${ }^{+}$. Consequently, Ti-Fe-Mus was positively charged at $\mathrm{pH}=3$ and 5 while negatively charged at $\mathrm{pH}=7,9$ and 11 . In addition, TBBPA has two proton-binding sites associated with the phenolic hydroxyl groups presenting different $\mathrm{pKa}$ values of 7.5 and 8.5 , respectively. ${ }^{60}$ Ogunbayo and Michelangeli ${ }^{61}$ determined a global value of pKa of TBBPA in aqueous solution $(9.8+/-0.3)$ thus a value higher than the above mentioned values. In the explored $\mathrm{pH}$ range, TBBPA exists in neutral molecular conformation $(\mathrm{pH}=3,5,7)$, and as a dissociated charged species (anion) with $\mathrm{pH}=9,11$. Since the surface of Ti-Fe-Mus was negatively charged with a $\mathrm{pH}$ higher than pzc, electrostatic repulsion between TBBPA and the surface of catalyst becomes dominating with a $\mathrm{pH}$ more raised, involving a reduction in the elimination of TBBPA.

The effect of various initial concentrations of TBBPA on the efficiency of photocatalytic degradation is shown in Fig. 11. Table 3 accounts for the data from Fig. 11 in terms of removal efficiency (\%), rate constant $k$ and half-life $t_{1 / 2}$ for TBBPA degradation. The degradation efficiency decreases significantly with the increase of the initial concentration of TBBPA. The maximum efficiency (90 wt.\%) was reached when the concentration of TBBPA was $90 \mathrm{ppm}$ together with the highest value of $\mathrm{k}\left(0.0350 \mathrm{~min}^{-1}\right)$. When the TBBPA concentration was increased to $300 \mathrm{ppm}$, only $60 \mathrm{wt} . \%$ of TBBPA were degraded. The rate constant $\mathrm{k}$ decreased with the increase of the initial concentration of TBBPA. This finding could be attributed to the high quantity of TBBPA, occupying active sites of the surface of the catalyst and, consequently, decreasing the path length of the photons entering the solution, thus generating a reduced number of oxidizing species. Consequently, the generation of hydroxyl radicals will be reduced and light irradiation will become less effective. Figure 11 also shows that the photocatalytic degradation of TBBPA follows pseudo-firstorder kinetics in agreement with other reports. ${ }^{57,58}$

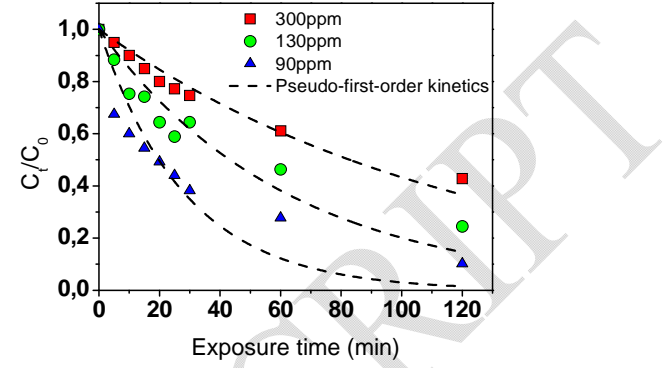

Fig. 11. Effect of initial concentration of TBBPA towards removal efficiency. Experimental conditions: Ti-Fe-Mus concentration $10 \mathrm{mg} /$ $25 \mathrm{~mL} ; \mathrm{pH}=3$ and $\mathrm{T}=25^{\circ} \mathrm{C}$.

Table 3. Kinetic parameters of TBBPA degradation, applying various initial TBBPA concentrations. Experimental conditions: Ti-Fe-Mus concentration $10 \mathrm{mg} / 25 \mathrm{~mL} ; \mathrm{pH}=3$ and $\mathrm{T}=25^{\circ} \mathrm{C}$.

\begin{tabular}{ccccc}
\hline $\mathrm{C}_{0}$ & $\mathrm{R}(120 \mathrm{~min})$ & $10^{2} \mathrm{k}$ & $\mathrm{t}_{1 / 2}$ & \\
$(\mathrm{ppm})$ & $(\%)$ & $\left(\mathrm{min}^{-1}\right)$ & $(\mathrm{min})$ & $\mathrm{R}^{2}$ \\
\hline 300 & 60 & 0.83 & 82.82 & 0.96 \\
130 & 76 & 1.60 & 43.32 & 0.89 \\
90 & 90 & 3.5 & 19.80 & 0.96 \\
\hline
\end{tabular}

The photocatalytic process implies many contradictory reactions. Figure 12 proposes a mechanism of the increased photocatalytic activity for the heterostructured Ti-Fe-Mus catalyst. The muscovite clay is known to be a very good electrical insulator. Consequently, the oxidation of TBBPA is initiated by photoexcitation of the semiconductor Ti-FeMus, followed by the formation of electron-hole pairs on the catalyst surface.

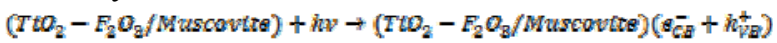

These holes react with water by producing highly reactive hydroxyl radicals $(\bullet \mathrm{OH})$, and the electrons can be trapped by $\mathrm{O}_{2}$ available on the surface, to initiate the presence of reactive species $\left(\mathrm{O}_{2}^{*-}\right)$ and then $\mathrm{H}_{2} \mathrm{O}_{2},{ }^{62,63}$ involving oxidation and further removal of TBBPA. The photoinduced electrons will form active oxygen species, in particular superoxide radical ion $O_{2}^{*-}$ and hydroxyl radical $\bullet \mathrm{OH}$, which react with the TBBPA molecules and degrade them effectively. The co-solvent THF also plays a significant role in the photocatalytic reaction because this solvent reacts not only as VB hole scavenger, but also as a donor of hydrogen atoms during the process of debromination. 
Fig. 12. Proposed photocatalytic process of TBBPA by Ti-Fe-Mus.

\section{Stability of photocatalyst}

The stability and thus the reusability of the Ti-Fe-Mus photocatalyst is a parameter of vital importance for practical applications. The ageing of the photocatalyst was therefore examined and efforts were made to optimize the regeneration process. Repeated photodegradation cycles were performed to examine the recyclability of Ti-Fe-Mus and to determine the degradation efficiency of TBBPA. After each photocatalytic cycle the catalyst was recovered from the reaction mixture by centrifugation, washed several times with $\mathrm{THF} / \mathrm{H}_{2} 0(80 / 20, \mathrm{~V} / \mathrm{V})$ and dried at $100^{\circ} \mathrm{C}$ in an oven. Measurements of the catalyst weight were performed before and after regeneration. No significant loss of catalyst was observed during this process.

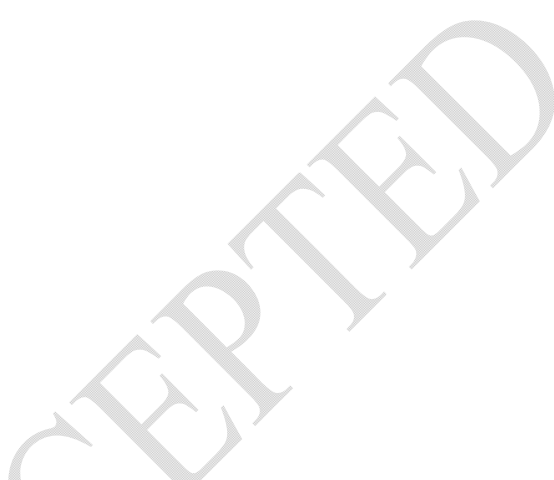

Fig. 13. Results from repeated application cycles of Ti-Fe-Mus catalyst for the photodegradation of TBBPA. Experimental conditions for each cycle : TBBPA concentration $300 \mathrm{ppm}$; Ti-Fe-Mus concentration $10 \mathrm{mg} /$ $25 \mathrm{~mL}$; exposure time $\mathrm{t}=120 \mathrm{~min} ; \mathrm{pH}=3$ and $\mathrm{T}=25^{\circ} \mathrm{C}$.

The reusability of Ti-Fe-Mus was investigated up to four cycles of TBBPA degradation. The results are shown in Fig. 13 , revealing that the photocatalytic activity of Ti-Fe-Mus was practically maintained after four successive degradation reactions with a slight decrease of the percentage of TBBPA degradation.

The chemical composition of the Ti-Fe-Mus recovered after the four cycles of photodegradation (REC) was analyzed and the data inserted into the Table 1 . Only minor changes in weight were observed for REC compared to pristine catalyst. In particular no significant difference in weight of $\mathrm{TiO}_{2}$ and $\mathrm{Fe}_{2} \mathrm{O}_{3}$ was found in both cases, indicating high stability of Ti-Fe-Mus under the chemical environment of photodegradation even after four application cycles.

\section{Conclusions}

In this work, a new photocatalyst made up of muscovite modified with titanium and iron was prepared by the method of impregnation and characterized by several analytical methods such as X-ray diffraction and nitrogen adsorption-desorption analysis. A high surface area and high photocatalytic performance could thus be obtained.

The synthesized catalyst effectively eliminated the persistent organic pollutant TBBPA from solution $\left(\mathrm{THF} / \mathrm{H}_{2} \mathrm{O}\right)$, definitively better than by photolysis. The effect of the $\mathrm{pH}$ revealed that the removal efficiency of TBBPA increased when the value of the $\mathrm{pH}$ decreased from 11 to 3, where TBBPA was in molecular form. The highest photocatalytic efficiency was obtained with an amount of catalyst of $0.4 \mathrm{~g} \mathrm{~L}^{-1}$ and an initial concentration of TBBPA of $90 \mathrm{ppm}$. Under these conditions, an elimination of 90 wt.\% of TBBPA was obtained after an exposure period of $120 \mathrm{~min}$. The kinetics of degradation of TBBPA followed the pseudo-first-order model. The mechanism proposed of TBBPA removal suggests multiple pathways of action on TBBPA by hydroxyl radicals.

\section{Acknowledgments}

The authors gratefully acknowledge the support of the Algerian Ministry of Higher Education and Scientific Research, University of Sciences and Technology (Oran/Algeria), CNRS, CAMPUSFRANCE, and University of Lille (France).

\section{References}

1. C. Yang et al., RSC Adv. 7, 23699 (2017).

2. Q. Jin et al., Funct. Mater. Lett. 10, 1750061 (2017).

3. L. Zhao et al., Funct. Mater. Lett. 12, 1950045 (2019).

4. M. T. Amin and A. A. Alazba, Mod. Phys. Lett. B 31, 1750264 (2017).

5. D. Ariyanti, M. Maillot and W. Gao, Int. J. Mod. Phys. B 31, 1744095 (2017).

6. V. Kavitha, P. S. Ramesh and D. Geetha, Int. J. Nanosci. 15, 1660002 (2016)

7. Y. Mahmiani, A. M. Sevim and A. Gül, J. Porphyr. Phthalocyanines 20, 1190 (2016).

8. R. Djellabia et al., J. Photochem. Photobiol. A Chem. 295, 57 (2014). 
9. D. Chen, H. Zhu and X. Wang, Appl. Surf. Sci. 319, 158 (2014).

10. Y. Zhang and H Yang, Funct. Mater. Lett. 6, 1350013 (2013).

11. N. K. Daud and B. H. Hameed, J. Hazard. Mater. 176, 938 (2010).

12. E. Dvininova et al., J. Hazard. Mater. 167, 1050 (2009).

13. J. Herney-Ramirez, M. A. Vicente and L. M. Madeira, Appl. Catal. B Environ. 98, 10 (2010).

14. J. G. Carriazo et al., Appl. Clay Sci. 50, 401 (2010).

15. J. G. Carriazo, A. Ensuncho-Muñoz and O. Almanza, Rev. Mex. Ing. Quim. 13, 473 (2014).

16. G. A. Knudsen et al., Toxicol. Appl. Pharmacol. 289, 323 (2015).

17. C. A. De Wit, D. Herzke and K. Vorkamp, Sci. Total Environ. 408, 2885 (2010).

18. J. R. Nyholm, C. Lundberg and P. L. Andersson, Environ. Pollut. 158, 2235 (2010)

19. Q. Li et al., Res. Chem. Intermediat. 45, 757 (2019).

20. Y. Guo et al., J. Hazard. Mater. 241-242, 301 (2012).

21. K. Bentaleb et al., J. Taiwan Inst. Chem. Eng. 80, 578 (2017).

22. S. J. Macnaughton et al., Modelling the leaching behaviour of an uranium ore, Uranium 2000, International symposium on the process metallurgy of uranium, (Saskatoon, Saskatchewan, Canada, 2000), pp. 413-428.

23. G. Horváth and K. Kawazoe, J. Chem. Eng. Jpn. 16, 470 (1983).

24. B. Faust, Modern Chemical Techniques: An Essential Reference for Students and Teachers, Ultraviolet/visible spectroscopy (RSC Publishing, 1997).

25. J. P. Chen, M.C. Hausladen and R.T. Yang, J. Catal. 151, 135 (1995).

26. P. Yuan et al., Micropor. Mesopor. Mater. 93, 240 (2006).

27. J. D. Ellis, G. A. K. Thompson, and A. G. Sykes, Inorg. Chem. 15, 3172 (1976).

28. S.A. Bagshaw and R.P. Cooney, Chem. Mater. 5, 1101 (1993).

29. C. Clinard et al., Clays Clay Miner. 51, 421 (2003).

30. P. Yuan et al., Micropor. Mesopor. Mater. 88, 8 (2006).

31. J. Liu and G. Zhang, Phys. Chem. Chem. Phys. 16, 8178 (2014).

32. T. Mandalia et al., Chem. Commun. 19, 2111 (1998).

33. P. Levitz and D. Tchoubar, J. Phys. I 2, 771 (1992).

34. S. A. Bagshaw, E. Prouzet and T. J. Pinnavaia, Science 269, $1242(1995)$

35. C. E. Fowler et al., Appl. Surf. Sci. 253, 5485 (2007).

36. A. C. S. Alcântara et al., Appl. Clay Sci. 39, 160 (2008).

37. M. Dondi et al., Appl. Clay Sci. 18, 145 (2001).

38. Practical identification of clay minerals: A Handbook for Teachers and Students in Clay Mineralogy, ed. J. Thorez, 1st edn. (G. Lelotte, Dison, 1976).

39. D. M. Moore and R. C. Reynolds, X-ray Diffraction and the Identification and Analysis of Clay Minerals, 2nd edn. (Oxford University Press, Oxford, 1989, 322, 321).

40. H. M. Köster, Clay Miner. 31, 417 (1996).

41. M. Önal, Appl. Clay Sci. 37, 74 (2007).

42. C. Volzone and A. M. Cesio, Mat. Res. 12, 191 (2009).

43. W. Guo et al., Energ. Explor. Exploit. 35, 463 (2017).
44. W. R. Caseri, R. A. Shelden and U. W. Suter, Colloid Polym. Sci. 270, 392 (1992).

45. V. M. Goldschmidt, Undersogelser over lersedimenter. Beretning om Nordiske Jordbrugsforskeres. Kongress I Osla Copenhagen, Nordisk Jordsbrugsforsning 4, 434-445 (1926).

46. V. C. Farmer, The Infrared Spectra of Minerals, ed. V. C. Farmer (Mineralogical Society, London, 1974), The layer silicates, pp. 331-363.

47. M. Vlasova, G. Dominguez-Patino, N. Kakazey et al., Sci. Sinter. 35, 155 (2003).

48. A. Eisazadeh, K. A. Kassim and H. Nur, E. J. G. E. (Electronic Journal of Geotechnical Engineering) 15, 327 (2010).

49. Z. Hubicki et al., Acta Phys. Pol. A 3, 312 (2009)

50. G. Akçay and M. K. Yurdakoc, Turk. J. Chem. 23, 105 (1999).

51. F. Gridi-Bennadji and P. Blanchart, J. Therm. Anal. Calorim. 90, 747 (2007).

52. P. Bansal and D. Sud, Desalination 267, 244 (2011).

53. S. K. Kansal, M. Singh and D. Sud, J. Hazard. Mater. 141, 581 (2007).

54. A. Akyol, H. C. Yatmaz and M. Bayramoglu, Appl. Catal. B Environ. 54, 19 (2004).

55. J. J. Pignatello, E. Oliveros and A. MacKay, Crit. Rev. Environ. Sci. Technol. 36, 1 (2006).

56. S. Rafqah et al., J. Photochem. Photobiol. A Chem. 199, 297 (2008).

57. Y. Zhong et al., J. Nanosci. Nanotechnol. 14, 7307 (2014).

58. N. Li et al., J. Mater. Sci. 52, 6937 (2017).

59. P. R. Gogate and A. B. Pandit, Adv. Environ. Res. 8, 501 (2004).

60. https://pubchem.ncbi.nlm.nih.gov/compound/Tetrabromobis phenol A\#section=Top.

61. O. A. Ogunbayo and F. Michelangeli, Biochem. J. 408, 407 (2007).

62. F. Hosseini et al., Mater. Sci. Semicond. Process. 83, 175 (2018).

63. R. Georgekutty, M. K. Seery and S. C. Pillai, J. Phys. Chem. C 112, 13563 (2008). 